RASĀYAN J. Chem.

Vol. 13 | No. 1 |333 - 338| January - March | 2020 ISSN: 0974-1496 | e-ISSN: 0976-0083 | CODEN: RJCABP

RJC http://www.rasayanjournal.com http://www.rasayanjournal.co.in

\title{
SYNTHESIS AND CHARACTERIZATION OF CROSS-LINKED TRI-POLYMERS OF POLY ACRYLIC ACID AS WATER THICKENING AGENTS
}

\author{
Zalak J. Patel ${ }^{1, *}$, Mukesh C. Patel ${ }^{1}$, Parimal M. Chatrabhuji ${ }^{1}$, \\ Viral A. Patel ${ }^{2}$ and Dharmesh R. Patel ${ }^{2}$ \\ ${ }^{1}$ Department of Chemistry, Pramukh Swami Science and H D Patel Arts College, HNG \\ University, Kadi, Gujarat-384 440 India \\ ${ }^{2}$ Department of Chemistry, HVHP Institute of Post Graduate Studies \& Research, \\ Kadi, Gujarat-384 440 India \\ *E-mail: zalak8466@gmail.com
}

\begin{abstract}
A cross-linked poly acrylic acid tri-polymer is successfully synthesized by batch charging polymerization of poly allyl tris buffer, di-vinyl benzene and acrylic acid and this new method is profitable in terms of reducing the toxicity, faster, purity and cheaper than available methods. The morphological structure of the synthesized polymer is studied by SEM and the characteristic functional groups of the synthesized polymers are identified using FTIR. TGA and DSC techniques were employed to study their thermal characterization.

Keywords: Poly allyl tris buffer, Di-vinyl Benzene, Acrylic Acid, Water-absorbing Agent, Copolymer Composition (C) RASĀYAN. All rights reserved
\end{abstract}

\section{INTRODUCTION}

Co-polymers of the carboxylic monomer for instance acrylic acid and $0.1-1.0$ by weight cross-linker like poly allyl tris buffer are gel-like polymers. These types of polymers are unsolvable in aqueous medium and other organic solvents. They are particularly in the type of their salts; suck up great quantities of water or other solvents with subsequent a numerous times raise in volume. The carboxylic polymers produced when a carboxylic monomer is copolymerized with a poly alkenyl polyether of a polyhydric alcohol. It is containing two or more alkenyl ether grouping per molecule. ${ }^{1-2}$

These carboxylic polymers are used in various fields such as thickeners, suspending agents and stabilizers. ${ }^{3-6}$ Polymers of a carboxylic acid monomer and acrylic esters having aliphatic long-chain containing at least $10-30$ carbon atoms can be used as thickeners when they are neutralized. They have superior resistance to reducing in viscosity when salt added thereto. ${ }^{7}$

Excessively spongy polymers are crossly linked polymer have a network like a sequence without dissolving and can retain just as grasp the vast volume of water in the swollen arrangement. The retained fluid is scarcely removable still under certain powers. ${ }^{8}$

The most frequently working synthetic polymers are evenly cross-linked carboxylic polymers primed from unsaturated carboxylic acid-containing monomers such as acrylic acid and maleic acid and anhydride. The cross-linked with unsaturated di-esters, di-vinyl benzene and others of carboxylic monomers are difficult to control in this polymerization. The various processes for synthesizing the higher carboxylic polymers are described in different Patents. ${ }^{9-11} \mathrm{pH}$-sensitive cross-linked AA/Gelatin hydrogels produced by free-radical polymerization in the presence of ammonium persulfate initiator and ethylene glycol di methacrylate cross-linking agent. Different feed ratios of acrylic acid, gelatin, and EGDMA were used to investigate the effect of monomer, polymer, and degree of cross-linking on swelling and release pattern of the model drug. ${ }^{13}$ Zinc oxide $(\mathrm{ZnO})$ Nano composite hydrogels are

Rasayan J. Chem., 13(1), 333-338(2020)

http://dx.doi.org/10.31788/RJC.2020.1315526

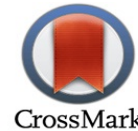


RASĀYAN J. Chem.

Vol. 13 | No. 1 |333 - 338| January - March | 2020

synthesized with free-radical polymerization in methanol using ammonium persulphate as the initiator at $60{ }^{\circ} \mathrm{C}$ temperature and $\mathrm{N}, \mathrm{N}$ - methylene bis acrylamide (MBA) as a crosslinker. ${ }^{14}$ The high swelling polymer hydrogel from epichlorohydrin with hydrolyzed polyacrylonitrile is synthesized and the swelling properties are identified. The effect of temperature and concentration is also analyzed. ${ }^{15}$ Gold nanoparticles are prepared with poly (acrylic acid) and cysteine, it is characterized by techniques. ${ }^{16}$

The present research studies have employed a new synthetic method for the preparation of the tri polymers of AA.

\section{EXPERIMENTAL}

For this research work allyl tris buffer, di-vinyl benzene, acrylic acid, ethanol and potassium thiosulphate all these reagents are of laboratory reagent grade. Basic glassware such as three-neck round bottom flask and mechanical stirrer and FT-IR spectrophotometer (Bruker alpha) were used.

A nitrogen gas inlet tube and mechanical stirrer are built-in with a three-necked round bottom flask of $1000 \mathrm{ml}$ capacity. Exactly $600 \mathrm{ml}$ of the solvent mixture is transferred into the flask and add the two small pieces of porcelain chips. Now gradually heat the solvent mixture to $60-65^{\circ} \mathrm{C}$ temperature and then pass the nitrogen gas to sparge the flask contents to oust the air. The 5 experimental runs (3.1-3.5) are set using varied amounts of allyl tris buffer $(1,0.8,0.6,0.4,0.2 \mathrm{~g})$ and relevant of acrylic acid and di-vinyl benzene added. At the same time, $1 \mathrm{~g}$ of an initiator potassium thiosulphate $\left(\mathrm{K}_{2} \mathrm{~S}_{2} \mathrm{O}_{8}\right)$ is added to initiate the polymerization and temperature is expanded by $4{ }^{\circ} \mathrm{C} / \mathrm{min}$ to reach $80^{\circ} \mathrm{C}$ and this temperature is maintained for $1.5 \mathrm{~h}$. During this heating period, the gelatinized polymer starts to produce within 50 minutes. The produced strong gel is dried for 24 hours. The dried solid is then used for further investigation. Then weigh $0.5 \mathrm{~g}$ solid polymer in a beaker to make suspense solution in $30 \mathrm{ml}$ water overnight. Then remove the excess amount of water from a beaker and the swollen product is neutralized with saturated $\mathrm{NaOH}$ at about $7.0 \mathrm{pH}$. The reaction mixtures employed are given in Table-1.

Table-1: Description of the Amount of Reagents

\begin{tabular}{c|c|c|c|c|c}
\hline Experiment & 3.1 & 3.2 & 3.3 & 3.4 & 3.5 \\
\hline Chemicals & Amount & Amount & Amount & Amount & Amount \\
\hline Allyl tris buffer & $1 \mathrm{~g}$ & $0.8 \mathrm{~g}$ & $0.6 \mathrm{~g}$ & $0.4 \mathrm{~g}$ & $0.2 \mathrm{~g}$ \\
\hline Di-vinyl benzene & $39 \mathrm{~g}$ & $39.1 \mathrm{~g}$ & $39.2 \mathrm{~g}$ & $39.3 \mathrm{~g}$ & $39.4 \mathrm{~g}$ \\
\hline Acrylic acid & $60 \mathrm{~g}$ & $60.1 \mathrm{~g}$ & $60.2 \mathrm{~g}$ & $60.3 \mathrm{~g}$ & $60.4 \mathrm{~g}$ \\
\hline Ini.- $\mathrm{K}_{2} \mathrm{~S}_{2} \mathrm{O}_{8}$ & $1 \mathrm{~g}$ & $1 \mathrm{~g}$ & $1 \mathrm{~g}$ & $1 \mathrm{~g}$ & $1 \mathrm{~g}$ \\
\hline Sol.- $\mathrm{H}_{2} \mathrm{O}+\mathrm{C}_{2} \mathrm{H}_{5} \mathrm{OH}$ & $490+10 \mathrm{ml}$ & $490+10 \mathrm{ml}$ & $490+10 \mathrm{ml}$ & $490+10 \mathrm{ml}$ & $490+10 \mathrm{ml}$ \\
\hline Neut. $-\mathrm{NaOH}$ & $7 \mathrm{pH}$ & $7 \mathrm{pH}$ & $7 \mathrm{pH}$ & $7 \mathrm{pH}$ & $7 \mathrm{pH}$ \\
\hline
\end{tabular}

\section{RESULTS AND DISCUSSION}

The polymer thickeners are identified by Fourier Transform Infrared (BROOKER FT-IR) Spectrophotometer using their $\mathrm{KBr}$ pellets and the representative IR spectrum of the polymer 3.1 is presented in Fig.-1. The spectra show that the main characteristic peaks are at $2924 \mathrm{~cm}^{-1}$ and $2855 \mathrm{~cm}^{-1}$. These are exhibited for the asymmetric stretching vibration of $(-\mathrm{C}=\mathrm{C}-\mathrm{H}$ Stretching) and asymmetric stretching vibration of $\mathrm{N}-\mathrm{H}$ of the secondary amine group. The strong peak at $1696 \mathrm{~cm}^{-1}$ confirmed $-\mathrm{C}=\mathrm{O}$ stretching of intermolecular hydrogen bonding of acrylic acid. Furthermore, the IR band at 1652 (merged, weak) $\mathrm{cm}^{-1}$ is owing to the characteristic stretching vibration of $-\mathrm{C}=\mathrm{C}$ bond. The peak at $1396 \mathrm{~cm}^{-1}$ is accredited to $\mathrm{O}-\mathrm{H}$ bending vibration. The band at $1156 \mathrm{~cm}^{-1}$ is recognized for $-\mathrm{C}-\mathrm{O}$ stretching of ether bending vibration.

The thermo gravimetric analysis (TGA) of the polymers was run using TG (Perkin Elmer TGA 8000 Thermo Gravimetric Analyzer). The thermograms indicate that degradation of a polymer starts around $150^{\circ} \mathrm{C}$ and degradation completed above $200^{\circ} \mathrm{C}$ temperature. Thus, it can be concluded that the prepared polymer thickeners are thermally stable up to $150^{\circ} \mathrm{C}$ and few are up to $250^{\circ} \mathrm{C}$. The canyons (converse peaks) are due to the fact that polymer has started to degrade as the impurity could be adhered in the form of aqueous phase or hydrocarbons and heat is liberated during degradation.

The cross-linking is also characterized by DSC analysis, as shown in Fig.-3. DSC of cross-linked thickener polymer indicates that a weight loss occurs within two stages. 
RASĀYAN J. Chem.

Vol. 13 | No. 1 |333 - 338| January - March | 2020

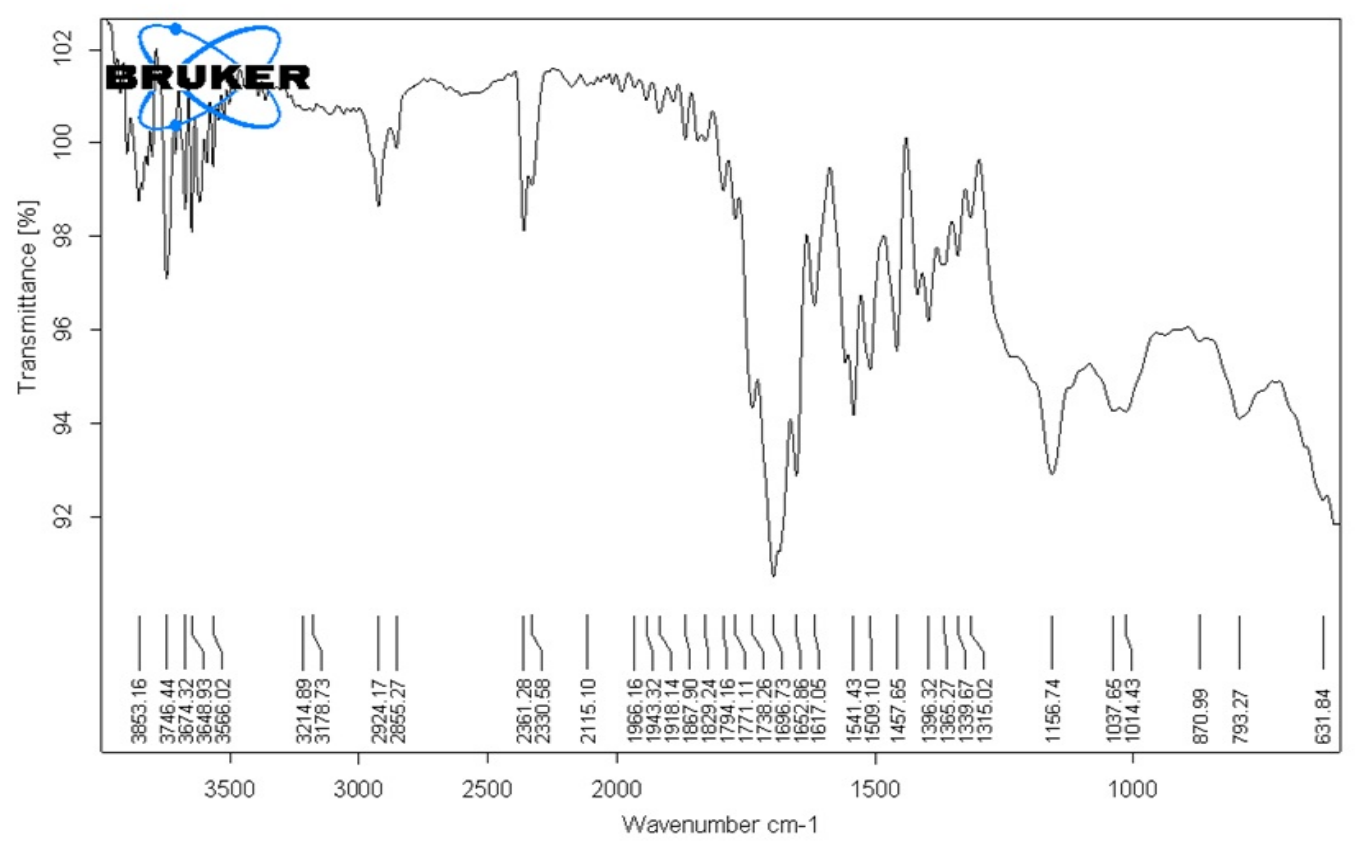

Fig.-1: FT-IR of Cross-linked Tri-polymer
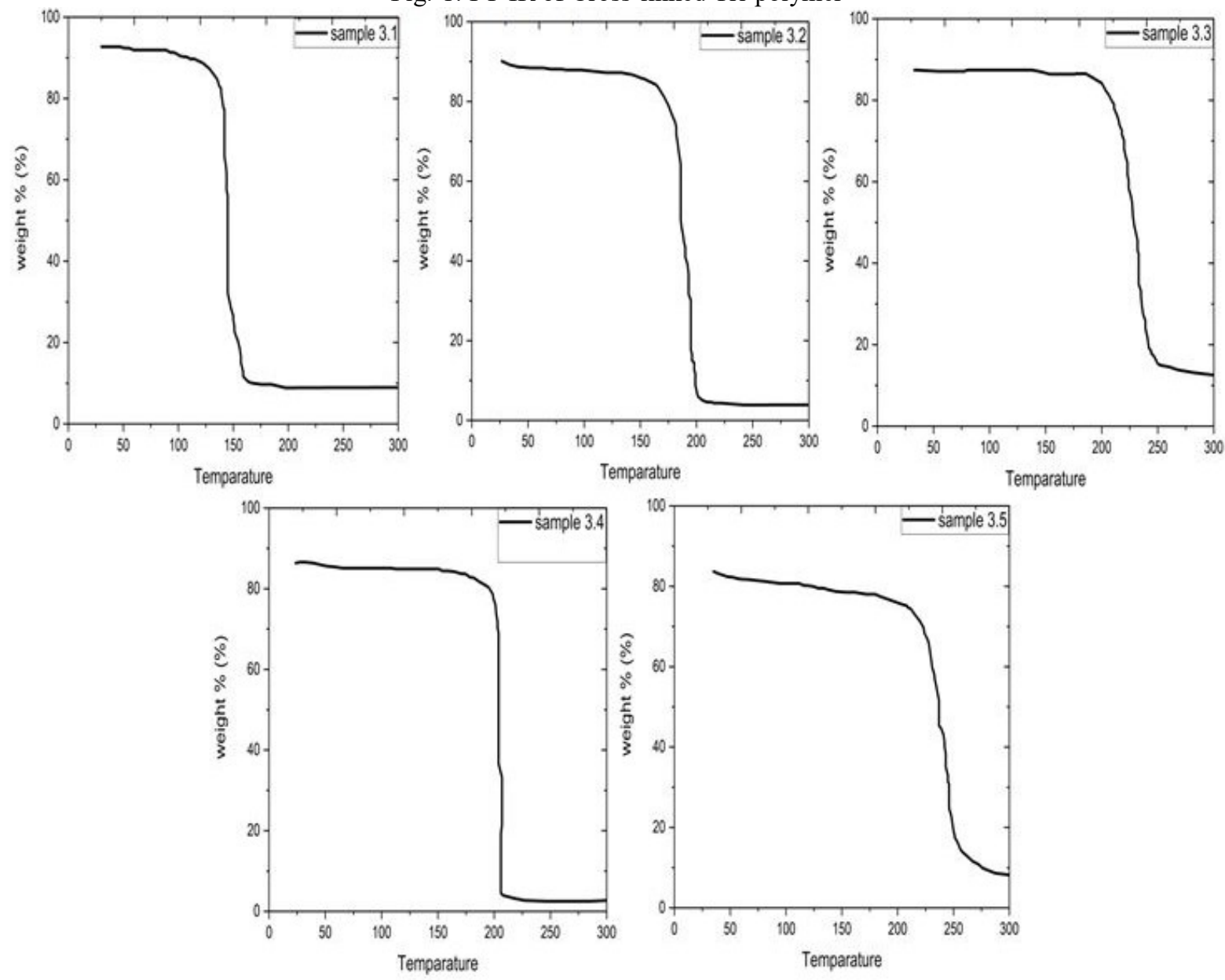

Fig.-2: TGA of Cross-linked Tri-polymers 
RASĀYAN J. Chem.

Vol. 13 | No. 1 |333 - 338| January - March | 2020

Essentially, acrylic acid has the glass-transition temperature $(\mathrm{Tg})$ is nearly $106^{\circ} \mathrm{C}$, but due to cross-linked with DVB, there may be slightly changed in $T_{g}$. DSC thermograms designate that $T_{g}$ of the polymer increases by about $115^{\circ} \mathrm{C}$ and is independent of the amount of allyl tris buffer. There is the hump in the bend and fix the midpoint in each curve as $T_{g}$. The initial stage shows weight loss is between $40^{\circ} \mathrm{C}$ and $125^{\circ} \mathrm{C}$ which might be due to the loss of absorbed and bound water. The next stage of mass loss started at $225^{\circ} \mathrm{C}$ and continued to $275^{\circ} \mathrm{C}$, during which weight loss may be due to the degradation of the crosslinker.
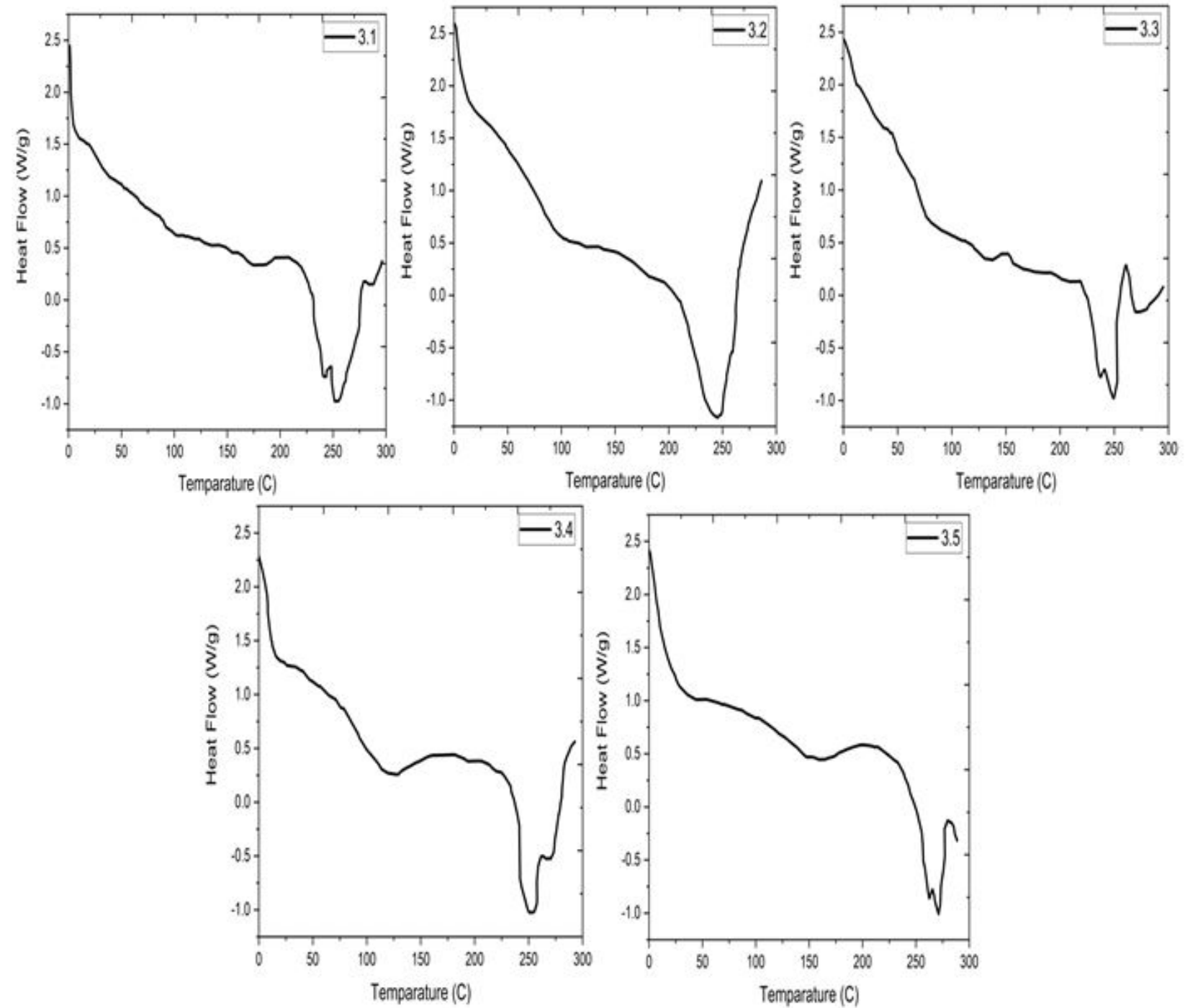

Fig.-3: DSC of Cross-linked Tri-polymers

SEM micrographs of structured cross-linked polymers are investigated and furnished in Fig.-4. The differences are obvious. The super absorbent polymer prepared from allyl tris buffer, acrylic acid and DVB cross-linking (Fig.-4b and c) have a solid amorphous nonporous shell. It can be observed that the fractographs are of a layer-like rough appearance (Fig.-4c), which indicates an adhesive interface. While the further two images of polymer thickeners prepared from DVB, acrylic acids and tris buffer monomers ATB shows different porosity. The highest porosity could be predicted from the monograph of polymer thickening agent cross-linked with ATB, the pores are associated with each other. The porosity can obviously be seen in the inflated view. However, in Fig.-4a aggregation of the porous structure can be seen and seems to be phase-separated. 

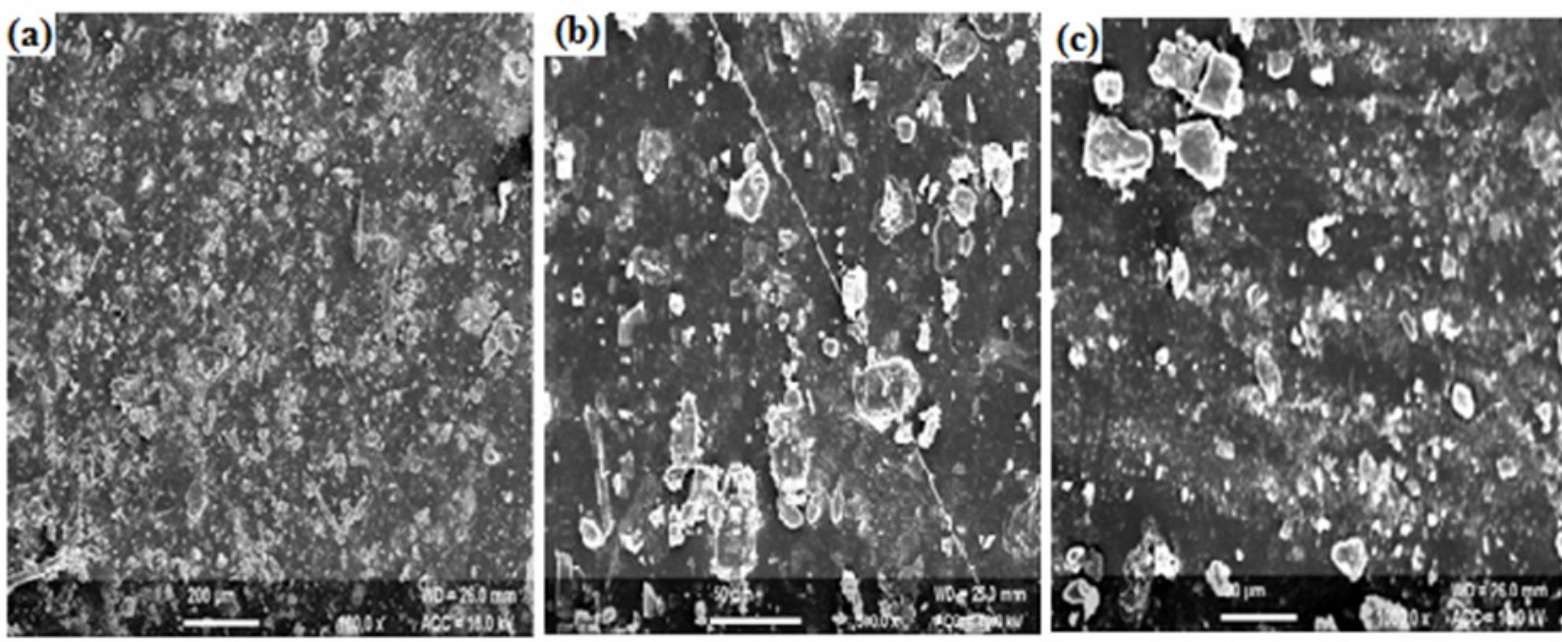

Fig.-4: SEM Micrographs of prepared SAP's shows for the Superabsorbent Polymer Cross-linked with PAA-ATB and Divinyl Benzene with Different Micro Sizes

Weight $0.5 \mathrm{~g}$ samples of absorbent polymer and placed into a beaker. The beaker is pre-weighed $\left(\mathrm{W}_{0}\right)$. The polymers are dipped in an excess quantity of water for the night to achieve the steadiness of swelling. After swelling, removes the excess volume of water waiting no fluid was drop-offs. The absorbed polymers are weighed (Ws) and the capacity of swelling is calculated by the equation:

Swelling capacity $=($ swollen/dry $) \times 100 \%$
$=\left(\mathrm{W}_{\mathrm{s}} / \mathrm{W}_{0}\right) \times 100 \%$
\begin{tabular}{c|c|c|c} 
Table-2: Absorbance Capacity of the Polymer \\
\hline $\begin{array}{c}\text { Weight of Cross- } \\
\text { linking Agent }(\mathrm{g})\end{array}$ & $\begin{array}{c}\text { Weight of } \\
\text { Sample }(\mathrm{g})\end{array}$ & $\begin{array}{c}\text { Weight of Swelled } \\
\text { Polymer }(\mathrm{g})\end{array}$ & $\begin{array}{c}\text { Swelling } \\
\text { Capacity } \%\end{array}$ \\
\hline 1.0 & 0.5 & 5.782 & 1057 \\
\hline 0.8 & 0.5 & 8.012 & 1502 \\
\hline 0.6 & 0.5 & 10.108 & 1922 \\
\hline 0.4 & 0.5 & 11.614 & 2223 \\
\hline 0.2 & 0.5 & 7.750 & 1450 \\
\hline
\end{tabular}

\section{CONCLUSION}

Allyl tris buffer is hydrophilic, acrylic acid is also hydrophilic but DVB is hydrophobic. Since divinyl benzene is far in excess compared to allyl tris buffer, the polymer segments of acrylic acid/DVB form of one phase and ally tris buffer with acrylic acid form the immiscible second phase. By using the presented synthetic method clear rubbery gel polymer product is achieved. The surface morphology and thermal behavior are studied using SEM and TGA techniques, respectively.

The DSC of cross-linked SAP with allyl tris buffer shows a weight loss at $40^{\circ} \mathrm{C}$. The super absorbent polymer synthesized from acrylic acid and the cross-linking agent has a solid smooth non-porous surface. Polymer started to degrade at about $150^{\circ} \mathrm{C}$ and completed nearly $260^{\circ} \mathrm{C}$. The cross-linking was also supported by DSC analysis. According to swelling property of SAPs which are absorbs a larger amount of water. SAPs have many applications. Superabsorbent polymers have the capacity to intellect environmental variations, changes of $\mathrm{pH}$, temperature. Hydrophilic networks are reactive to some molecules that can be used as in drug systems, hygienic products like diapers, and in controlled release drugs. ${ }^{12}$ Superabsorbent polymers were also employed in various applications, such as absorbent paper products, bandages and surgical pads, wound dressings, and as chemical absorbents. Additionally, they are applicable to food packaging. ${ }^{1}$

The polymers are characterized using SEM patterns and FTIR spectra. The following conclusions are made based on the results and discussion. 
RASĀYAN J. Chem.

Vol. 13 | No. 1 |333 - 338| January - March | 2020

i. $\quad$ FTIR spectra exhibit the cross-linking of monomers and cross-linker.

ii. From the swelling analysis, the newly synthesized polymers are absorbing more amount of water content, and they can be, therefore, employed as a super absorbent in various applications.

iii. In the DSC thermograms, weight loss may occur due to the degradation of the cross-linker.

iv. It can be observed that the SEM fractographs are of a layer-like rough appearance solid amorphous non-porous shell.

\section{ACKNOWLEDGMENT}

The authors are thankful to the Research Laboratory of Pramukh Swami Science and H D Patel Arts College, Kadi for providing research facilities.

\section{REFERENCES}

1. H. P. Brown, US Patent No. 2, 798, 053 (1957), DOI: patent/US2798053A/en

2. M. Zief and E. Yanovsky, US Patent No. 2, 606, 881 (1952), DOI: patent/US2606881

3. N. W. Taylor and E. B. Bagley, Journal of Applied Polymer Science, 21(1), 113(1977), DOI:10.1002/app.1977.070210110

4. K. M. Raju and M. P. Raju, Advances in Polymer Technology, 20(2), 146 (2001), DOI: $10.1002 / \mathrm{adv} .1012$

5. G. Yildiz, H. Çatalgil-Giz, F. Kadirgan, Journal of Applied Electrochemistry, 30(1), 71(2000), DOI:10.1023/A:1003884301844

6. D. Laba, Rheological Properties of Cosmetics and Toiletries, Thirteen ${ }^{\text {th }}$ edition, Marcel Dekker, New York, pp 55-153 (2017).

7. K. S. Robert, US Patent No. 3,915,921 (1975), DOI: patent/US3915921A/en

8. James H. Allison, Harish C. Agrawal, Blake W.Moore, Analytical Biochemistry, 58(2), 592(1974), DOI: $10.1016 / 0003-2697(74) 90228-0$

9. F. D.A. Gaetano, US Patent No. 2,340,110 (1944), DOI: patent/US2340110A/en

10. F. D.A. Gaetano, US Patent No. 2,340,111 (1944), DOI: patent/US2340111A/en

11. B. S. Raymond, US Patent No. 2,533,635 (1950), DOI: patent/US2533635

12. L.C.Davies, J.M.Novais, S. Martins-Dias, Environmental Technology, 25 (1) 89 (2004), DOI: $10.1080 / 09593330409355441$

13. S. Khan, S. M. H. Bukhari, M. Rehanullah, and N.M. Ranjha, International Journal of Polymer Science, 2015, 1 (2015), DOI: 10.1155/2015/187961

14. K. Bharathi and P. Pazhanisamy, Rasayan Journal of Chemistry, 11(4), 1721 (2018), DOI: $10.31788 /$ RJC.2018.1142072

15. R. Zh. Omirova , A. A. Bolysbek, Sh. D. Shirinov and A.T. Dzhalilov, Rasayan Journal of Chemistry, 12(4), 2047 (2019), DOI:10.31788/RJC.2019.1245331

16. E. R. Wikantyasning, M. Mutmainnah, Z. Cholisoh, I. Hairunisa , M.F.A. Bakar and M. Da'I, Rasayan Journal of Chemistry, 12(4), 1857 (2019), DOI:10.31788/RJC.2019.1245209

[RJC-5526/2019] 